\title{
In vivo Immunomodulatory Potential of Aqueous Extract of Different Parts of Terminalia catappa $\mathrm{L}$.
}

\author{
P. VENKATALAKSHMI* AND P. BRINDHA ${ }^{1}$ \\ PG and Research Department of Biochemistry, S. T. E. T. Women's College, Mannargudi, Tamil Nadu; ${ }^{1}$ Centre for advanced \\ research in Indian System of Medicine, SASTRA University, Thanjavur, Tamil Nadu
}

\section{Venkatalakshmi et al.: Immunomodulatory Potential of Terminalia catappa $\mathrm{L}$}

\begin{abstract}
Modulation of immunity is the most sought therapeutic effect as many human ailments arise because of imbalance in immune mechanisms. In the current corona virus disease scenarios also, the role of immunity to combat the dreadful virus has been well emphasized. Hence the present study aims at evaluating the immunomodulatory potential of aqueous extract obtained from the different parts such as bark, fruit and wood of Terminalia catappa. Based on the results obtained in acute oral toxicity and dose fixation studies, medium dose $(250 \mathrm{mg} / \mathrm{kg}$ body weight) of selected plant extracts were administered for $14 \mathrm{~d}$ to swiss albino mice to evaluate nonspecific (neutrophil adhesion, phagocytic index) and specific (hemagglutination antibody titer, delayed type hypersensitivity) immunomodulatory properties. The results obtained for plant extract treated groups were compared with cyclophosphamide (immunosuppressant) treated and levamisole (immunostimulant) treated mice. From the data of the results obtained it could be concluded that selected parts of Terminalia catappa have immune stimulatory as well as anti-inflammatory properties, thereby proving their efficacy as true immunomodulators. Among the parts selected, fruits exhibited significant immunomodulatory potential followed by bark and wood.
\end{abstract}

Key words: Immunomodulation, biological activity, Terminalia catappa, umbrella tree

The concept of immunomodulation has been gaining much significance worldwide as people started realizing the indispensable role of the immune system in maintaining a disease-free state. In the corona virus disease (COVID-19) pandemic also, the role of immunity to combat the virus is being emphasized by health professionals ${ }^{[1]}$. Immunomodulation refers to any changes in the immune response and may involve strengthening or suppression of the indicators of cellular and humoral immunity. Stimulation of the immune response is desired for certain people like immunocompromised patients, whereas suppression of the immune response is desired for others such as transplant recipients or patient with autoimmune or inflammatory diseases ${ }^{[2]}$. Although several synthetic drugs are being used in immunotherapy, the adverse side effects associated with their usage such as nephrotoxicity, anemia, thrombocytopenia, bone marrow suppression etc., has produced an awareness to limit their usage and to search for safe alternatives. The use of traditional knowledge and practices in the process of drug discovery could lead to better success ${ }^{[3]}$. Several plants from Ayurvedic texts have been studied

*Address for correspondence E-mail: venkatalakshmisathish@gmail.com

May-June 2021 for their immunomodulatory properties and found to have the potential of providing new scaffolds for safer, synergistic, cocktail immunodrugs ${ }^{[4]}$.

Terminalia catappa L. (T. catappa), a large spreading umbrella tree belonging to the family Combretaceae, is distributed throughout the tropics in coastal environments. Different solvent extracts of leaves and bark of $T$. catappa have been reported to exhibit antibacterial ${ }^{[5,6]}$, anti-fungal ${ }^{[7]}$, anti-inflammatory ${ }^{[8,9]}$, antioxidant and anti-tumor ${ }^{[10]}$ activities. Presence of Isorhamnetin in bark, fruit and wood, Rottlerin and Limocitrin in bark and wood and Iristectorin-A in fruit and wood has been revealed through Liquid Chromatography-Electron Spray IonizationMass Spectrometry (LC-ESI-MS/MS) analysis ${ }^{[11]}$. Fruits of T. catappa are rich in flavonoids such as

\footnotetext{
This is an open access article distributed under the terms of the Creative Commons Attribution-NonCommercial-ShareAlike 3.0 License, which allows others to remix, tweak, and build upon the work non-commercially, as long as the author is credited and the new creations are licensed under the identical terms
} 
Quercetin-3-Glucuronide, Quercetin-3,4'-O-di-betaglucopyranoside, Geniposide, Rutin, Hesperetin, Flavanomarein, Kaempferol-7-neohesperidoside, Baccatin, Isorhamnetin, Peonidin, Iristectorin-A, Scoparin, Tricin, Cirsiliol and Isorhamnetin-3Glucoside-4'-Glucoside, which might be responsible for the invitro cytotoxic effect of the fruit extract in controlling Ehrlich Ascites Carcinoma (EAC) cell lines ${ }^{[11]}$. Earlier, acute oral toxicity studies were carried out to ascertain the safety of the selected plant extracts. Swiss albino mice of female sex (20-25 g) were used for acute toxicity studies. Single dose oral administration of test extracts at a concentration of $2000 \mathrm{mg} / \mathrm{kg}$ body weight, caused no adverse toxic effects on the body weight, feed intake and gross anatomy of treated female Swiss mice ${ }^{[12]}$. It was also found that aqueous extracts of bark, fruit and wood of TC had the potential to restore normalcy in altered hematological and biochemical profiles of cyclophosphamide induced cytotoxicity ${ }^{[13]}$. Despite these therapeutic potentials, evidences are scanty to prove the immunomodulatory properties of bark, fruits, and wood of T. catappa. Hence, the present study has been taken up with an objective to evaluate the immunomodulatory potentials of aqueous extract of different parts of $T$. catappa in Swiss albino mice.

\section{MATERIALS AND METHODS}

Selected plant parts such as bark, fruits and wood of T. catappa L. for the proposed study were collected from farm fields in and around Mannargudi, Tamil Nadu, India. The botanical identity was authenticated by comparing with the herbarium specimen deposited at RAPINAT Herbarium, St. Joseph's College, Tiruchirappalli, Tamil Nadu, India (Voucher specimen number P.N.001/2012). The aqueous extracts of selected parts of $T$. catappa were prepared as per standard procedure ${ }^{[14]}$.

\section{Experimental animals:}

The animal experiments were carried out as per Organisation for Economic Co-operation and Development (OECD) guidelines $(2001)^{[15]}$. The study was conducted after the approval by the Institutional Animal Ethical Committee, SASTRA deemed University (Indian Atomic Energy Commission (IAEC) Approval Number: 166/SASTRA/IAEC/ RPP). Swiss albino mice of either sex were used to assess immunomodulatory potential of the selected plant sources. The animals were 8-12 w old. The mice were fed with commercial pellet rat chow purchased from M/s. Provimi Animal Nutrition India Pvt. Ltd., Bangalore, India and Reverse osmosis (RO) water $a d$ libitum. Temperature of the test room was maintained between $22 \pm 3^{\circ}$ and relative humidity between 50 to $70 \%$ during the experimental period. The experimental room was provided with a $12 \mathrm{~h}$ light and $12 \mathrm{~h}$ dark lighting condition using an automatic timer. Standard polypropylene mice cages with stainless steel top grill was used to house the animals. The cages were autoclaved. Sieved and sterilized paddy husk was used as the bedding material. Animals were housed individually. Bedding material, cages, grills and water bottles were changed weekly twice.

\section{Study design:}

Study was planned in such a manner to conduct non specific immune response and specific immune response using separate set of animals. For non-specific immune response evaluation, animals were divided in to five groups with $n=6$. For the evaluation of specific immune response, another set of animals were divided in to ten groups, each comprising of twelve mice.

\section{Evaluation of nonspecific immune response:}

Dosage of aqueous extracts of bark, fruits, and wood of $T$. catappa selected for the immunomodulatory studies was $250 \mathrm{mg} / \mathrm{kg}$. Animals were divided in to five groups, each comprising of six mice. Group I animals served as control and received vehicle only (Distilled water). Group II animals were treated with Levamisole $(50 \mathrm{mg} / \mathrm{kg} /$ p.o. $)$ and Group III, IV, V animals were treated with Aqueous extract of $T$. catappa bark, fruits, wood (250 mg/kg., p.o.) respectively.

\section{Neutrophil adhesion test:}

After $14 \mathrm{~d}$ of gastric gavage treatment, blood samples were collected in heparinized vials from animals in each group by retro-orbital puncture and subjected to total as well as differential leukocyte count. After performance of the initial counts, each blood sample was incubated with $80 \mathrm{mg} / \mathrm{ml}$ of nylon fibers at $37^{\circ}$ for $15 \mathrm{~min}$. The incubated samples were again analyzed for total and differential leukocyte count. The product of total leukocyte count and the percentage (\%) neutrophil (known as neutrophil index) was determined for each animal of the respective groups ${ }^{[16]}$. The percentage neutrophil adhesion for each of the test animal was then calculated as Neutrophil Adhesion $(\%)=(\mathrm{NIu}-\mathrm{Nit}) /$ $\mathrm{NIu} \times 100$ 
where NIu-neutrophil index of the blood samples before nylon fibre treatment; NIt-index after nylon fiber treatment.

\section{Carbon-Clearance test for the determination of phagocytic index:}

Animals were divided in to 5 groups having six animals in each group. After $14 \mathrm{~d}$, animals of all the groups received intravenous injection of Indian ink $(0.3 \mathrm{ml}$ per $30 \mathrm{~g}$ ) via the tail vein. Blood samples from retro-orbital venous plexus were taken and mixed with $4 \mathrm{ml}$ of $0.1 \%$ Sodium carbonate solution and the absorbance of this solution was determined at $660 \mathrm{~nm}$ at $0 \mathrm{~min}$ and $15 \mathrm{~min}$. Recorded absorbance was plotted against the time. This absorbance explains the rate of elimination of carbon from the blood. The phagocytic index was calculated using the following equation ${ }^{[17]}$.

Phagocytic index $(\mathrm{K})=\left(\log _{\mathrm{e}} \mathrm{OD} 1-\log _{\mathrm{e}} \mathrm{OD} 2\right) / 15$

OD1 $=$ optical densities at 0 minutes and, OD2=optical densities at $15 \mathrm{~min}$, respectively.

\section{Evaluation of specific immune response:}

Animals were divided in to ten groups, each comprising of twelve mice. Treatments were given to each group as follows. Mice from all groups were immunized by injecting $0.1 \mathrm{ml}$ of $20 \%$ Sheep Red Blood Cells (SRBCs) intraperitoneally (i.p.) on $7^{\text {th }} \mathrm{d}$ and $14^{\text {th }} \mathrm{d}$. Six animals from each group were subjected for the evaluation of Humoral antibody response and remaining 6 animals were subjected to evaluate cell mediated immune response.

Group I Immunized Control: Vehicle only (Distilled water)

Group II Negative Control: Cyclophosphamide (100 mg/kg/p.o.) $3^{\text {rd }}, 6^{\text {th }}, 9^{\text {th }} \mathrm{d}$

Group III Standard Drug: Levamisole (50 mg/kg/p.o.)

Group IV, V, VI: Aqueous extract of T. catappa bark, fruit, wood $(250 \mathrm{mg} / \mathrm{kg} / \mathrm{p}$.o.) respectively

Group VII: Cyclophosphamide ((100 mg/kg/p.o.) $3^{\text {rd }}$, $6^{\text {th }}, 9^{\text {th }} \mathrm{d}+$ Levamisole $(50 \mathrm{mg} / \mathrm{kg} / \mathrm{p}$. .o. $)$

Group VIII: Cyclophosphamide ((100 mg/kg/p.o.) $3^{\text {rd }}, 6^{\text {th }}, 9^{\text {th }} \mathrm{d}+$ Aqueous extract of $T$. catappa bark (250 mg/kg., p.o.)

Group IX: Cyclophosphamide ((100 mg/kg/p.o.) $3^{\text {rd }}, 6^{\text {th }}, 9^{\text {th }} \mathrm{d}+$ Aqueous extract of $T$. catappa fruits (250 mg/kg., p.o.)
Group X: Cyclophosphamide ((100 $\mathrm{mg} / \mathrm{kg} /$ p.o.) $3^{\text {rd }}, 6^{\text {th }}, 9^{\text {th }} \mathrm{d}+$ Aqueous extract of $T$. catappa wood (250 mg/kg., p.o.)

\section{Hemagglutination test (Humoral antibody response):}

The Sheep Red Blood Cells (SRBC) agglutination test was performed to study the humoral antibody response against antigens. Mice $(n=6)$ from all groups were immunized by injecting $0.1 \mathrm{ml}$ of $20 \%$ SRBCs intraperitoneally (i.p.) on $7^{\text {th }} \mathrm{d}$ and $14^{\text {th }} \mathrm{d}$. The blood samples were collected from individual animals of all the groups by retro orbital bleeding on $14^{\text {th }} \mathrm{d}$ for Primary Antibody titer and on $21^{\text {st }} \mathrm{d}$ for secondary Antibody titer. Serum was separated from blood. Hemagglutination Antibody titers were determined by following the Hemagglutination technique, which is performed using 96 -wells $(12 \times 8)$ bottomed titer plate (fig. 1). The wells were marked from 1 to 12. In the first well, $25 \mu \mathrm{l}$ of serum collected from treated animals is added and afterwards $25 \mu$ l of Phosphate-buffered saline (PBS) was added to all the wells except well number 12 and mixed well. The last well on each row contained sterile normal saline as control. Then $25 \mu 1$ of sample from $1^{\text {st }}$ well was taken and added to $2^{\text {nd }}$ well and again $25 \mu \mathrm{l}$ from $2^{\text {nd }}$ well was taken and added to $3^{\text {rd }}$ well and the same procedure was followed up to well number 11. Later $25 \mu 1$ of sample from well number 11 was discarded and finally $25 \mu 1$ of $1 \%$ suspension SRBCs was added to all the wells and incubated $\left(37^{\circ}\right.$ per $\left.1 \mathrm{~h}\right)$. Each well was examined for Hemagglutination. The reciprocal of highest dilution of the test serum giving agglutination was taken as the antibody titer. The data obtained were subjected to statistical analysis ${ }^{[18-19]}$.

\section{Delayed type hypersensitivity (DTH):}

Mice $(\mathrm{n}=6)$ from each group were immunized on $7^{\text {th }} \mathrm{d}$ and $14^{\text {th }} \mathrm{d}$ with SRBC in normal saline $(0.1 \mathrm{ml}$ of $20 \%$ SRBCs) intraperitoneally and challenged on $21^{\text {st }} \mathrm{d}$ with $0.03 \mathrm{ml}$ of $20 \%$ SRBCs in sub plantar region of left hind paw. The thickness of the right hind paw was measured before challenge. After $24 \mathrm{~h}$ and $48 \mathrm{~h}$ thickness of footpad was measured by Vernier calipers. Difference in the footpad thickness before and after challenge was taken as the measure of the Delayed-type hypersensitivity (DTH) reaction ${ }^{[20]}$. Estimation of Superoxide dismutase (SOD) ${ }^{[21]}$, Catalase $(\mathrm{CAT})^{[22]}$, Lipid peroxidase ${ }^{[23]}$, Reduced Glutathione ${ }^{[24]}$ were carried out and Histopathological studies of spleen of experimental animals were carried out ${ }^{[25]}$. 


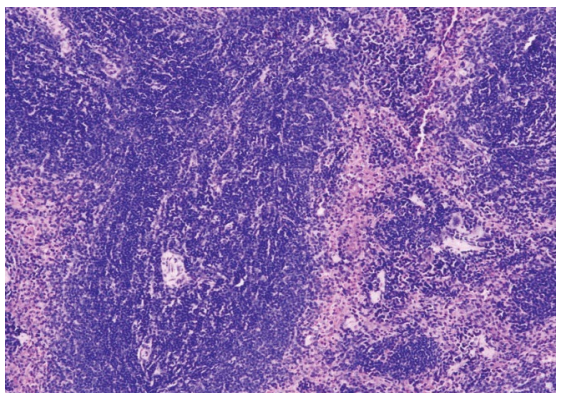

(1) Immunized Control

No significant alteration

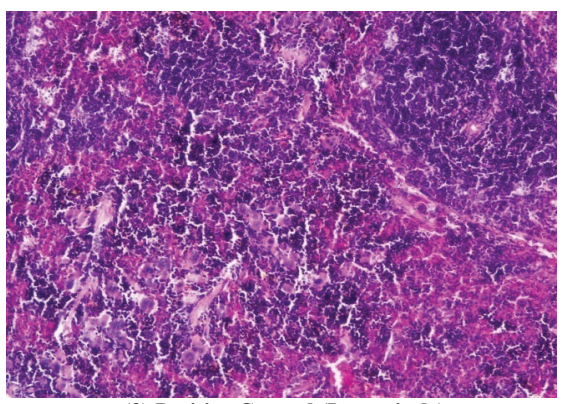

(3) Positive Control (Levamisole)

Mild hypercellularity in follicle of white pulp minimal increase in red pulp cellularity

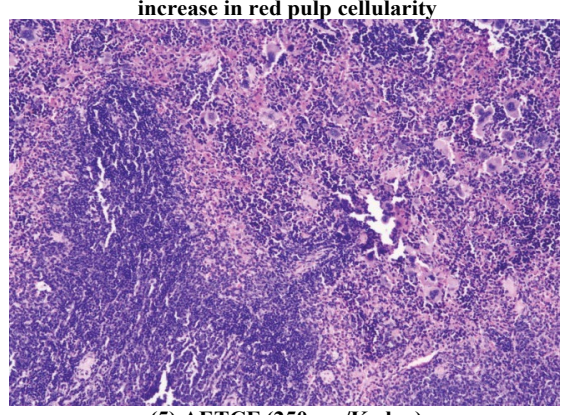

(5) AETCF (250 mg/Kg bw)

Mild hypercellularity in follicle of white pulp minima increase in red pulp cellularity

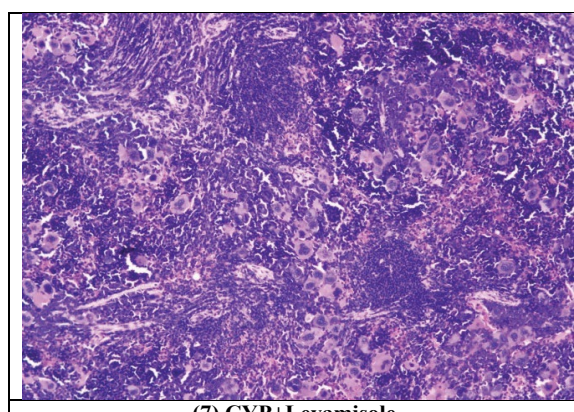

(7) CYP+Levamisole

Minimal hypocellularity of white pulp moderate increase in red pulp cellularity

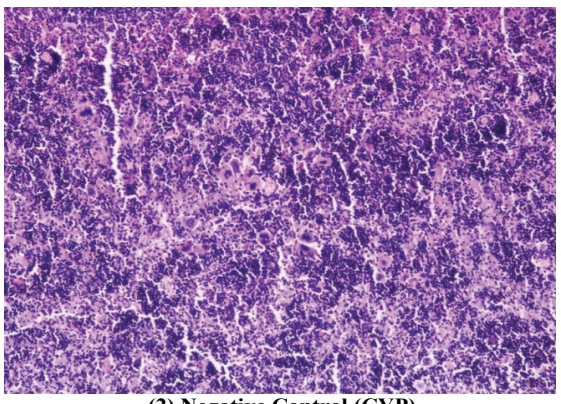

(2) Negative Control (CYP)

Mild hypocellularity in

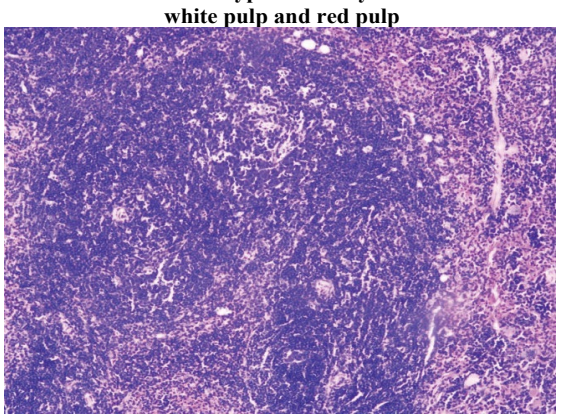

(4) AETCB (250 mg/Kg bw)

Mild hypercellularity in follicle of white pulp minima increase in red pulp cellularity

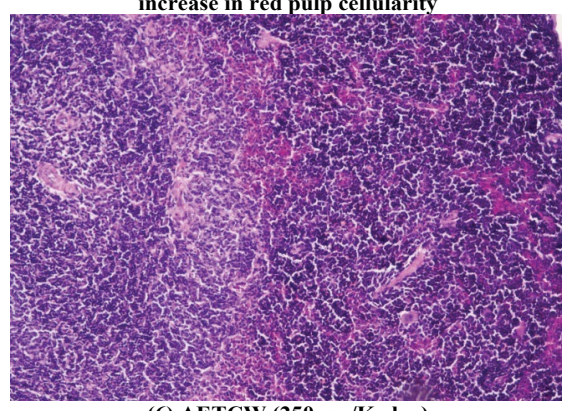

(6) AETCW (250 mg/Kg bw)

Mild hypercellularity in follicle of white pulp minima increase in red pulp cellularity

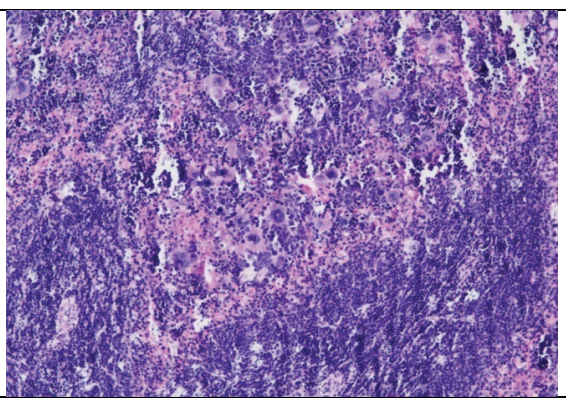

(8) CYP+AETCB (250 mg/Kg bw)

Minimal hypocellularity of white pulp moderate increase in red pulp cellularity

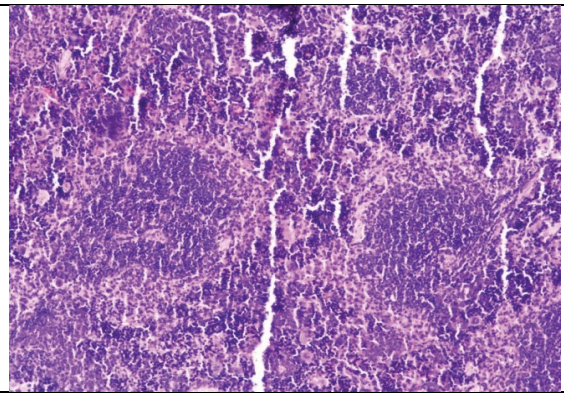

(9) CYP+AETCF (250 mg / Kg bw)

Minimal hypocellularity of white pulp moderate increase in red pulp cellularity

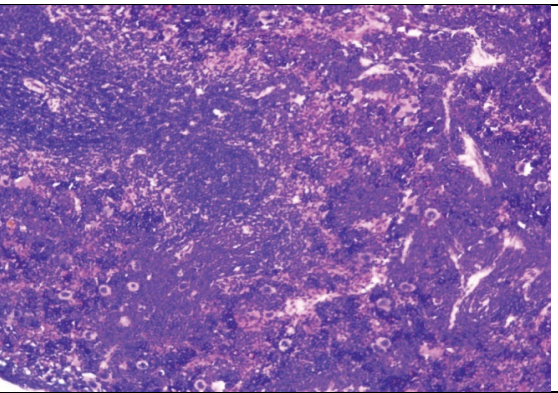

(10) CYP+AETCW (250 mg/Kg bw)

Minimal hypocellularity of white pulp moderate increase in red pulp cellularity

Fig. 1: Photomicrographs of Histopathological studies-Spleen 


\section{Statistical Analysis:}

All the results were expressed as mean \pm Standard error of the mean (SEM). The data were statistically analyzed by one-way analysis of variance (ANOVA) followed by Tukey's multiple comparisons. Statistical presentations were organized using Graph Pad Prism Software, Windows version 6.0. Inter group comparison were carried out and $\mathrm{p}$ values $<0.05, \mathrm{p}<0.01$ and $\mathrm{p}<0.001$ were considered significant.

\section{RESULTS AND DISCUSSION}

The recruitment and attachment to the endothelium is a critical step in the initiation of the inflammatory response. The neutrophil adhesion to nylon fibers describes the margination of polymorphonuclear lymphocyte in the blood vessels and the number of macrophages reaching the site of inflammation ${ }^{[26]}$. In the present study aqueous extracts of bark, fruits and wood of T. catappa $(250 \mathrm{mg} / \mathrm{kg}, \mathrm{p}$. o), showed a substantial rise in the neutrophil adhesion to nylon fibers. Highly significant increase in neutrophil adhesion was observed in the case of Levamisole (Standard immunostimulant) and fruit extract treated group when compared with control. There was no significant difference between fruits and standard. Non-significant increase in neutrophil adhesion was observed in bark and wood treated groups. Among the test extracts selected, fruits exhibited high degree of neutrophil adhesion followed by bark and wood (Table 1). This might be due to the upregulation of the $\beta 2$ integrins, present on the surface of the neutrophils through which they adhere firmly to the nylon fibres ${ }^{[27]}$. Neutrophils play an important role in host immune mechanism. From the results obtained, it was inferred that test extracts caused stimulation and margination of neutrophils towards the site of inflammation thereby proved their efficiency to enhance nonspecific immunity.

The reticuloendothelial system (RES) is a diffuse system consisting of phagocytic cells. Cells of the RES play a vital role in the clearance of particles from the bloodstream. When colloidal carbon particles in the form of ink are injected directly into the systemic circulation, the rate of clearance of carbon from the blood by macrophage is governed by an exponential equation ${ }^{[28]}$. In view of pivotal role played by the macrophages in coordinating the processing and presentation of antigen to B cells, the selected plant extracts were evaluated for their effect on phagocytic index of macrophages. The test extracts showed remarkable augmentation in the phagocytic index. Highly significant increase in the phagocytic index was observed in the animals treated with levamisole, fruit extract and bark extract respectively as compared with control. There was no significant difference in the values obtained for levamisole and fruit extract. Wood extract produced a slight increase in phagocytic index than control which was statistically insignificant (Table 2). From the data obtained, it is observed that enhanced phagocytic index of fruits was more followed by bark and wood, which might be due to increase in the activity of the reticulo endothelial system in the clearance of granular foreign bodies from the circulation.

In the studies for specific immunomodulation, no significant changes were observed in the body weight

TABLE 1: EFFECT OF AETC ON NEUTROPHIL ADHESION

\begin{tabular}{lccccccc}
\hline \multirow{2}{*}{ Groups } & \multicolumn{2}{c}{ TLC $\left(\right.$ Cells/mm ( $^{3}$ (A) } & \multicolumn{2}{c}{ Neutrophils \% (B) } & \multicolumn{2}{c}{ Neutrophil index (A×B) } & Neutrophil \\
\cline { 2 - 6 } & UB & NFTB & UB & NFTB & UB & NFTB & Adhesion \% \\
\hline I & $4.19 \pm 0.24$ & $4.18 \pm 0.24$ & $57.83 \pm 8.20$ & $52 \pm 8.17$ & $241.24 \pm 26.54$ & $216.36 \pm 26.03$ & $10.38 \pm 0.9830$ \\
II & $5.75 \pm 0.39$ & $5.66 \pm 0.39$ & $64 \pm 5.93$ & $32.66 \pm 7.76$ & $368.78 \pm 43.72$ & $181.99 \pm 43.78$ & $51.20 \pm 2.523^{*}$ \\
III & $4.52 \pm 0.75$ & $4.51 \pm 0.75$ & $56.66 \pm 6.05$ & $41.16 \pm 3.76$ & $257.35 \pm 53.34$ & $186.77 \pm 38.42$ & $27.28 \pm 2.419^{\#}$ \\
IV & $5.03 \pm 0.57$ & $4.96 \pm 0.58$ & $59.66 \pm 2.80$ & $35.33 \pm 3.98$ & $300.18 \pm 35.68$ & $176.88 \pm 36.04$ & $41.52 \pm 2.584^{*}$ \\
V & $4.35 \pm 0.57$ & $4.34 \pm 0.57$ & $57 \pm 4.14$ & $46.33 \pm 6.59$ & $247.01 \pm 22.63$ & $201.06 \pm 35.58$ & $19.04 \pm 3.517^{\#}$ \\
\hline
\end{tabular}

Values are Mean \pm SEM $(n=6)$ values are significant when ${ }^{*} p<0.001,{ }^{*} p<0.01, \cdot p<0.05$ vs Control , I-Control, II-Positive control (Levamisole), III-Aqueous extract of T. catappa Bark, IV-Aqueous extract of T. catappa Fruit, V-Aqueous extract of T. catappa wood, UB -Untreated blood, NFTB- Nylon Fiber treated blood

TABLE 2: EFFECT OF AETC ON PHAGOCYTIC INDEX

\begin{tabular}{lccc}
\hline Groups & Initial OD & Final OD & Phagocytic Index \\
\hline I & $0.573 \pm 0.04$ & $0.54 \pm 0.04$ & $0.007 \pm 0.002$ \\
II & $0.516 \pm 0.06$ & $0.349 \pm 0.01$ & $0.048 \pm 0.007^{*}$ \\
III & $0.575 \pm 0.04$ & $0.430 \pm 0.04$ & $0.036 \pm 0.002^{*}$ \\
IV & $0.663 \pm 0.10$ & $0.433 \pm 0.91$ & $0.050 \pm 0.001^{*}$ \\
V & $0.500 \pm 0.064$ & $0.438 \pm 0.048$ & $0.016 \pm 0.001^{\#}$ \\
\hline
\end{tabular}

Values are Mean \pm SEM $(n=6)$ values are significant when ${ }^{*} p<0.001,{ }^{*} p<0.01,{ }^{*} p<0.05$ vs Control 
of the experimental animals throughout the study period. Marginal weight gain was observed in the animals treated with levamisole and test extracts but the weight gain was not significant. Cyclophosphamide treated animals were presented with a decrease in body weight. There was a slight reduction in the weight of spleen in group II animals due to the cytotoxic effect of cyclophosphamide, where as in all the other group's insignificant increase was observed in the weight of spleen (Table 3).

Hemagglutination antibody titer was determined to establish the humoral response against SRBC antigen. The antibody production of $T$ dependent antigen SRBC requires the co-operation of $\mathrm{T}$ and $\mathrm{B}$-lymphocytes and macrophages. In the present study, the augmentation of the humoral response was evidenced by an enhancement of primary and secondary antibody titers to SRBC in experimental animals indicating the enhanced responsiveness of macrophages and B lymphocytes subsets involved in antibody synthesis. Decrease in the production of primary and secondary antibody titer against SRBC was observed in cyclophosphamide treated group when compared with immunized control group. But the difference was not significant. Highly significant increase in the antibody titer was observed in groups treated with levamisole and fruits respectively. The values were highly significant even when these groups were co treated with cyclophosphamide. There was no significant difference in the values of levamisole and fruit treated groups. Followed by fruits, bark extract produced significant increase in antibody titer when compared with group II. Even though wood extract produced increase in antibody titer than control and cyclophosphamide treated groups, the values were found to be statistically significant only against group II and insignificant against group I. The data of the results suggested that fruits had shown enhanced humoral immune response as comparable to the standard immunostimulant Levamisole. In the case of bark and wood their activity was not equivalent to levamisole, but still their potential in enhancing humoral response was evident (Table 4).

Several lines of evidence suggest that DTH reaction is important in host defense against parasites and bacteria that can live and proliferate intracellularly ${ }^{[29-30]}$. In the present study, test extracts showed increase in foot pad thickness when measured after $24 \mathrm{~h}$ of SRBC challenge. Administration of cyclophosphamide in animals reduced mean foot pad thickness in group II as compared to immunized control. Among the test extracts, fruits produced foot pad thickness comparable with levamisole. All the three extracts significantly enhanced the foot pad thickness even in the presence of cyclophosphamide, which reveals that the test materials have effect on T-cells and may play a role in providing immunity against parasite and bacterial intracellular proliferation. Fruits have exhibited much better cell mediated immune response followed by bark and wood (Table 5).

Ingeneral,normalinflammationis rapidand self-limiting, but aberrant resolution and prolonged inflammation causes various chronic disorders ${ }^{[31]}$. Similarly, in the present study also, the inflammatory response which was produced to counteract SRBC challenge in $24 \mathrm{~h}$ was normalized within $48 \mathrm{~h}$. The results obtained in the in vivo experiments are on par with the results of antiinflammatory studies carried out in vitro. Earlier studies on species of Echinacea suggested its immunostimulant as well as anti-inflammatory properties ${ }^{[32]}$. Earlier reports suggest that many plant extracts have exhibited immunostimulant as well as anti-inflammatory efficacies which are much needed criterion to prove

\section{TABLE 3: EFFECT OF AETC ON BODY WEIGHT AND WEIGHT OF SPLEEN}

\begin{tabular}{lrrrrrc}
\hline \multirow{2}{*}{ Groups } & \multicolumn{3}{c}{ Body weight (g) } & \multicolumn{2}{c}{ Weight of spleen(g) } \\
\cline { 2 - 7 } I & Day 0 & Day 7 & Day 14 & Day 21 & Weight of Spleen (g) & Organ weight index (\%) \\
II & $28.20 \pm 3.63$ & $32.18 \pm 3.79$ & $26.00 \pm 3.33$ & $26.01 \pm 3.36$ & $0.122 \pm 0.03$ & $0.5 \%$ \\
III & $26.94 \pm 4.69$ & $25.06 \pm 4.61$ & $23.71 \pm 4.88$ & $20.67 \pm 4.39$ & $0.106 \pm 0.03$ & $0.5 \%$ \\
IV & $22.27 \pm 2.58$ & $22.71 \pm 1.87$ & $26.06 \pm 3.18$ & $27.98 \pm 3.64$ & $0.131 \pm 0.05$ & $0.5 \%$ \\
V & $22.94 \pm 3.34$ & $22.96 \pm 4.45$ & $24.06 \pm 4.67$ & $24.83 \pm 5.15$ & $0.165 \pm 0.05$ & $0.7 \%$ \\
VI & $22.78 \pm 3.56$ & $23.38 \pm 4.96$ & $23.99 \pm 3.00$ & $25.54 \pm 3.33$ & $0.140 \pm 0.02$ & $0.5 \%$ \\
VII & $21.25 \pm 3.64$ & $21.99 \pm 1.32$ & $22.34 \pm 2.19$ & $23.64 \pm 4.50$ & $0.133 \pm 0.05$ & $0.6 \%$ \\
VIII & $26.06 \pm 3.16$ & $24.41 \pm 2.20$ & $24.04 \pm 3.28$ & $21.58 \pm 1.33$ & $0.141 \pm 0.05$ & $0.7 \%$ \\
IX & $27.41 \pm 2.22$ & $26.92 \pm 3.00$ & $22.98 \pm 4.84$ & $22.30 \pm 3.55$ & $0.216 \pm 0.14$ & $1.0 \%$ \\
X & $26.05 \pm 4.85$ & $27.00 \pm 4.03$ & $26.04 \pm 4.84$ & $23.77 \pm 4.25$ & $0.136 \pm 0.03$ & $0.6 \%$ \\
\hline Valuenyyyyy
\end{tabular}

Values are Mean \pm S.D. ( $\mathrm{n}=12$ ) I-Immunized Control, II-Negative Control (CYP-Cyclophosphamide), III-Levamisole (LEV), IV, V, VI-aqueous extracts of T. catappa bark, fruit, wood respectively, VII-CYP+LEV, VIII, IX, X -CYP+aqueous extracts of T. catappa bark, fruit, wood respectively 
TABLE 4: EFFECT OF AETC ON HAEMAGGLUTINATION ANTIBODY TITER

\begin{tabular}{|c|c|c|c|}
\hline Groups & Primary Antibody Titer & Secondary Antibody Titer & \% Change in antibody titer compared with Control \\
\hline $\mathrm{I}$ & $3.5 \pm 0.28$ & $3.75 \pm 0.25$ & 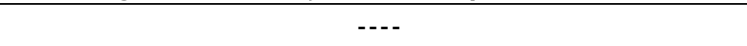 \\
\hline II & $2.5 \pm 0.28$ & $3 \pm 0.41$ & $\downarrow 20 \%$ \\
\hline III & $8.25 \pm 0.48^{* a}$ & $8.75 \pm 0.25^{* a}$ & $\uparrow 133 \%$ \\
\hline IV & $5.25 \pm 0.63^{b}$ & $5.5 \pm 0.28^{\# \mathrm{~b}}$ & $\uparrow 47 \%$ \\
\hline V & $6 \pm 0.41^{\# a}$ & $7.5 \pm 0.28^{* a}$ & $\uparrow 100 \%$ \\
\hline VI & $4.75 \pm 0.25^{c}$ & $5.25 \pm 0.48^{b}$ & $\uparrow 40 \%$ \\
\hline VII & $7 \pm 0.41^{* a}$ & $7.75 \pm 0.25^{* a}$ & $\uparrow 106 \%$ \\
\hline VIII & $4.5 \pm 0.29 c$ & $5.25 \pm 0.25^{b}$ & $\uparrow 40 \%$ \\
\hline IX & $5.5 \pm 0.29 \cdot a$ & $6.75 \pm 0.25^{* a}$ & $\uparrow 80 \%$ \\
\hline$x$ & $4.25 \pm 0.48$ & $4.75 \pm 0.48^{b}$ & $\uparrow 27 \%$ \\
\hline
\end{tabular}

Values are Mean $\pm \operatorname{SEM}(n=6)$ values are significant when ${ }^{*} p<0.001,{ }^{\#} p<0.01, \cdot p<0.05$ vs Immunized control ${ }^{a} p<0.001,{ }^{b} p<0.01,{ }^{c} p<0.05$ vs negative control

TABLE 5: EFFECT OF AETC ON DELAYED TYPE HYPERSENSITIVITY

\begin{tabular}{|c|c|c|c|c|c|c|c|c|}
\hline \multirow[b]{2}{*}{ Groups } & \multirow{2}{*}{$\begin{array}{l}\text { Mean footpad } \\
\text { thickness } \\
(\mathrm{mm}) \text { before } \\
\text { challenge }(\mathrm{A})\end{array}$} & \multicolumn{3}{|c|}{ After challenge at 24 Hours } & \multicolumn{3}{|c|}{ After challenge at 48 Hours } & \multirow{2}{*}{$\begin{array}{c}\% \text { of } \\
\text { recovery to } \\
\text { normalcy } \\
\text { in } 48 \mathrm{hrs}\end{array}$} \\
\hline & & $\begin{array}{c}\text { Thickness in } \\
\text { mm (B) }\end{array}$ & $\begin{array}{c}\text { Difference } \\
\text { in } \mathrm{mm} \\
(\mathrm{B}-\mathrm{A})\end{array}$ & $\begin{array}{l}\% \text { of paw } \\
\text { volume }\end{array}$ & $\begin{array}{c}\text { Thickness in } \\
\mathrm{mm}(\mathrm{C})\end{array}$ & $\begin{array}{l}\text { Difference } \\
\text { in } \mathrm{mm} \\
(\mathrm{C}-\mathrm{A})\end{array}$ & $\begin{array}{l}\% \text { of paw } \\
\text { volume }\end{array}$ & \\
\hline I & $2.31 \pm 0.38$ & $3.10 \pm 0.29$ & $0.79 \pm 0.62$ & 34 & $2.90 \pm 0.28$ & $0.59 \pm 0.60$ & 26 & 74 \\
\hline II & $2.15 \pm 0.18$ & $2.19 \pm 0.22$ & $0.08 \pm 0.12$ & 3 & $2.17 \pm 0.23$ & $0.02 \pm 0.13$ & 1 & 99 \\
\hline III & $1.95 \pm 0.17$ & $3.40 \pm 0.45$ & $1.45 \pm 0.51$ & 74 & $1.98 \pm 0.42$ & $0.03 \pm 0.50$ & 2 & 98 \\
\hline IV & $2.25 \pm 0.37$ & $3.36 \pm 0.37$ & $1.11 \pm 0.53$ & 49 & $2.32 \pm 0.36$ & $0.30 \pm 0.52$ & 3 & 97 \\
\hline V & $2.31 \pm 0.33$ & $3.67 \pm 0.32$ & $1.36 \pm 0.29$ & 59 & $2.38 \pm 0.30$ & $0.07 \pm 0.27$ & 3 & 97 \\
\hline VI & $2.23 \pm 0.46$ & $3.03 \pm 0.30$ & $0.80 \pm 0.48$ & 36 & $2.36 \pm 0.31$ & $0.13 \pm 0.46$ & 6 & 94 \\
\hline VII & $2.11 \pm 0.34$ & $3.43 \pm 0.60$ & $1.32 \pm 0.37$ & 63 & $2.13 \pm 0.58$ & $0.02 \pm 0.36$ & 1 & 99 \\
\hline VIII & $2.22 \pm 0.21$ & $2.97 \pm 0.43$ & $0.76 \pm 0.50$ & 34 & $2.34 \pm 0.42$ & $0.12 \pm 0.49$ & 5 & 95 \\
\hline IX & $2.12 \pm 0.44$ & $3.49 \pm 0.61$ & $1.37 \pm 0.39$ & 65 & $2.26 \pm 0.60$ & $0.14 \pm 0.38$ & 7 & 93 \\
\hline$X$ & $2.38 \pm 0.51$ & $3.13 \pm 0.31$ & $0.75 \pm 0.51$ & 32 & $2.47 \pm 0.30$ & $0.09 \pm 0.52$ & 4 & 96 \\
\hline
\end{tabular}

Values are mean \pm SEM $(n=6)$

a plant drug to be a true immunomodulator. This is possible because of the classical and alternative pathways of macrophage activation. Macrophages are involved in both innate and adaptative immune responses. Depending on the types of cytokines that macrophages are exposed to, these cells are subjected to classical (Th1) or alternative (Th2) activation. In the first case, macrophages, particularly are activated by interferon gamma (IFN- $\alpha$ ) or by lipopolysaccharide (LPS) and have the capacity, through the production of Nitric Oxide (NO) and other intermediates to destroy the remaining microorganisms in the inflammatory loci. However, excessive inflammatory immune responses mediated by classical macrophage activation can also be detrimental to the host. In contrast, the Interleukin (IL)-4 receptor-alpha-mediated alternative pathway of macrophage activation has been proposed as a mechanism to attenuate excessive inflammation. In the second case, after exposure to cytokines such as IL-4, IL-10 or IL-13, macrophages produce polyamines and proline, which induce proliferation and collagen production, respectively. Interestingly, in both classical and alternative activation, the essential substrate that drives these pathways is the amino acid arginine. NO synthase $2\left(\mathrm{NOS}_{2}\right)$ is induced by IFN-alpha or LPS and degrades arginine into Hyroxy-arginine and then into NO. Arginase is induced by Th2-type cytokines, which convert arginine into ornithine and subsequently into polyamines and proline ${ }^{[33-34]}$.

SOD and CAT are the most important enzymes in ameliorating the effects of oxygen metabolism. SODs are a family of endogenous antioxidant enzymes which act as the first line of defense system against ROS and are important in the catalytic decomposition of the superoxide radical into oxygen and hydrogen peroxide while catalases are enzymes that catalyze the conversion of hydrogen peroxide to water and oxygen. In the present study decrease in the levels of these enzymes was found in cyclophosphamide treated animals, as compared to immunized control mice and this decrease might be due to generation of excessive free radicals and increased lipid peroxidation. The activities of SOD and CAT were restored in the test drug treated groups 
TABLE 6: EFFECT OF AETC ON ENDOGENOUS ANTIOXIDANTS

\begin{tabular}{lcccc}
\hline Groups & SOD (U/mg) & CAT $(\mathrm{U} / \mathrm{mg})$ & LPO $(\mathrm{nM} / \mathrm{ml})$ & $\mathrm{GSH}(\mu \mathrm{g} / \mathrm{ml})$ \\
\hline I & $4.85 \pm 0.34$ & $0.4 \pm 0.03$ & $276.5 \pm 2.91$ & $8.75 \pm 0.29$ \\
II & $2.6 \pm 0.40^{*}$ & $0.15 \pm 0.01^{*}$ & $468.5 \pm 33.32^{*}$ & $3.85 \pm 0.16^{*}$ \\
III & $5.9 \pm 0.08^{\circ \mathrm{a}}$ & $0.28 \pm 0.02^{\mathrm{a}}$ & $306.5 \pm 4.69^{\mathrm{a}}$ & $6.95 \pm 0.25^{* \mathrm{a}}$ \\
IV & $6.2 \pm 0.04^{\# \mathrm{a}}$ & $0.33 \pm 0.02^{\mathrm{a}}$ & $309 \pm 5.81^{\mathrm{a}}$ & $7.8 \pm 0.22^{* \mathrm{a}}$ \\
V & $5.6 \pm 0.08^{\mathrm{a}}$ & $0.33 \pm 0.004^{\mathrm{a}}$ & $261 \pm 1.34^{\mathrm{a}}$ & $7.1 \pm 0.13^{* \mathrm{a}}$ \\
VI & $5.4 \pm 0.04^{\mathrm{a}}$ & $0.3 \pm 0.004^{\circ \mathrm{a}}$ & $305 \pm 9.84^{\mathrm{a}}$ & $9.1 \pm 0.13^{\mathrm{a}}$ \\
VII & $5.35 \pm 0.25^{\mathrm{a}}$ & $0.40 \pm 0.02^{\mathrm{a}}$ & $394.5 \pm 3.80^{* \mathrm{c}}$ & $5.15 \pm 0.20^{* \mathrm{~b}}$ \\
VIII & $5.45 \pm 0.16^{\mathrm{a}}$ & $0.275 \pm 0.01^{* \mathrm{a}}$ & $314 \pm 25.04^{\mathrm{a}}$ & $5.25 \pm 0.16^{* \mathrm{~b}}$ \\
IX & $5.45 \pm 0.25^{\mathrm{a}}$ & $0.345 \pm 0.02^{\mathrm{a}}$ & $321 \pm 15.65^{\mathrm{a}}$ & $5.05 \pm 0.11^{* \mathrm{c}}$ \\
X & $5.3 \pm 0.22^{\mathrm{a}}$ & $0.355 \pm 0.02^{* \mathrm{a}}$ & $278.5 \pm 6.93^{\mathrm{a}}$ & $6.1 \pm 0.13^{* \mathrm{a}}$ \\
\hline Valus
\end{tabular}

Values are Mean \pm SEM $(n=6)$ values are significant when ${ }^{*} p<0.001,{ }^{*} p<0.01,{ }^{\circ} p<0.05$ vs Immunized control ${ }^{a} p<0.001,{ }^{b} p<0.01$, ${ }^{c} \mathrm{p}<0.05$ vs negative control

further suggesting the antioxidant potential of the test extracts (Table 6).

The oxidation of membrane's lipid molecules causes damage resulting in the development of several physiological and pathological disorders. The inhibition of lipid peroxidation by any means is the best way to avoid these disorders in the body ${ }^{[35]}$. Elevation of lipid peroxides in the mice treated with cyclophosphamide indicated the degree of free radical induced cytotoxicity, which was brought back to near normal values in the test extract treated groups.

Glutathione is the major endogenous antioxidant produced by the cells, participating directly in the neutralization of free radicals and reactive oxygen compounds, as well as maintaining the exogenous antioxidants such as vitamins $\mathrm{C}$ and $\mathrm{E}$ in their reduced (active) forms. Through the direct conjugation, it detoxifies many xenobiotics (foreign compounds) and carcinogens ${ }^{[36]}$. It is essential for the immune system to exert its full potential in modulating the antigen presentation to lymphocytes, influencing the cytokine production; enhancing the proliferation of lymphocytes, enhancing the killing activity of cytotoxic T-cells and natural killer cells, and regulating apoptosis thereby maintaining the homeostasis of the immune system. Cyclophosphamide induced decrease in the level of glutathione was normalized by the test extracts and thereby proved their protective role against free radical induced oxidative stress.

Spleen of the animals belonging to immunized control group showed normal appearance with no significant pathological or morphological alterations. In the case of animals treated with cyclophosphamide mild decrease in all the regions of white pulp was observed along with mild to moderate increase in the cellularity of red pulp. In the case of standard treatment, no decrease in white pulp cellularity was observed and was comparable to that of control. However, increased cellularity in red pulp (mild) was observed in standard treatment also. In the case of animals treated with test extracts, there was no decrease in cellularity of white pulp as well as red pulp and the sections were comparable to control. In animals treated with test extracts, along with cyclophosphamide, there was only minimal hypocellularity of white pulp with mild to moderate hypercellularity in red pulp suggesting extramedullary hemopoiesis in red pulp.

Taken together, this dissertation provides new evidence that the selected parts of T. catappa have immunostimulatory as well as anti-inflammatory properties, thereby proving their efficacy as true immunomodulators. Among the parts selected, fruits exhibited significant immunomodulatory potential followed by bark and wood. These data provided novel evidence to support the immunomodulatory properties of selected parts of T. catappa and will help justifying the traditional use of T. catappa in pathogenic infections and inflammatory conditions through immunomodulation.

\section{Acknowledgements:}

Authors record their sincere gratitude to S.T.E.T. Women's College, Mannargudi, Thiruvarur District, Tamil Nadu. Authors extend their sincere gratitude to SASTRA Deemed University, Thirumalaisamudram, Thanjavur for the facilities provided to carry out animal experiments.

\section{Conflict of interest:}

Conflict of interest declared none.

\section{REFERENCES}

1. Mrityunjaya M, Pavithra V, Neelam R, Janhavi P, Halami PM, Ravindra PV. Immune-boosting, antioxidant and antiinflammatory food supplements targeting pathogenesis of 
COVID-19. Front Immunol 2020;11:570122.

2. Wagner H. Structural Analysis of a rhamnoarabinogalactan and arabinogalatans with immunostimulating activity from Calendula officinalis. Phytochemistry 1999;28(9): 2379-2383.

3. Patwardhan B, Vaidya ADB, Chorghade M. Ayurveda and natural products drug discovery. Curr Sci 2004;86: 789-799.

4. Rege NN, Thatte UM, Dahanukar SA. Adaptogenic properties of six rasayana herbs used in Ayurvedic medicine. Phytother Res 1999;13: 275-91.

5. Neelavathi P, Venkatalakshmi P, Brindha P. Antibacterial activities of aqueous and ethanolic extracts of Terminalia catappa leaves and bark against some pathogenic bacteria. Int J Pharm Pharm Sci 2013;5(1)114-20.

6. Sangavi R, Venkatalakshmi P, Brindha P. Anti-bacterial activity of Terminalia catappa L. bark against some bacterial pathogens. World J Pharm Pharm Sci 2015;4(9):987-92.

7. Gandhi P, Venkatalakshmi P, Brindha P. Efficacy of Terminalia catappa L. wood and bark against some fungal species. Int J Cur Microbiol App Sci 2015;4(9):74-80.

8. Sivaranjani C, Venkatalakshmi P, Brindha P. In vitro antiinflammatory and antioxidant activities on fruits of Terminalia catappa L. Res J Pharm Tech 2015;8(10):1409-11.

9. Venkatalakshmi $\mathrm{P}$, Brindha $\mathrm{P}$, Vadivel V. In vitro antioxidant and anti-inflammatory studies on bark, wood, and fruits of Terminalia catappa L. Int J Phytomed 2015;7(3):246-53.

10. Venkatalakshmi P, Brindha $\mathrm{P}$, Induja K. In vitro antioxidant and anti-tumour activities of Terminalia catappa bark. Int $\mathbf{J}$ Pharm Pharm Sci 2014;6(1):1-3.

11. Venkatalakshmi P, Vadivel V, Brindha P. Identification of flavonoids in different parts of Terminalia catappa L. using LC-ESI-MS/MS and investigation of their anticancer effect in EAC cell line model. J Pharm Sci Res 2016;8(4):176-83.

12. Venkatalakshmi $P$ and Brindha P. Studies on the acute oral toxicity profiles of a traditional drug source Desa Badama. Int J Pharm Sci 2020;11(3): 95-9.

13. Venkatalakshmi P, Brindha P. Protective effect of different parts of Terminalia catappa in the hematological and biochemical profiles of immunosuppressed mice. Ann Phytomed 2020;9(2):1-10.

14. Brindha P, Sasikala B, Purushothaman K. Phytochemical analysis of E. alba. BMEBR 1981;3(1):84-96.

15. OECD O. Guidance document on acute oral toxicity testing. 2001.

16. Wilkinson PC: Neutrophil adhesion test. In: Vane JK, Ferreria SH. Handbook of Experimental Pharmacology 1978: 109.

17. Manika D, Dasgupta SC, Gomes A. Immunomodulatory and antineoplastic activity of common Indian toad (Bufo melanostictus, Schneider) skin extract. Ind J Pharmacol 1998;30(5):311.

18. Puri A, Saxena R, Saxena RP, Saxena KC, Srivastava V, Tandon JS. Immunostimulant agents from Andrographis paniculata. J Nat Prod Res 1993;56:995-9.

19. Makare N, Bodhankar S, Rastogi V. Immunomodulatory activity of alcoholic extract of Mangifera indica L. in mice. J Ethanopharmacol 2001;78:133-7.

20. Dikshit V, Damre AS, Kulkarni KR, Gokhale A, Saraf MN. Preliminary screening of immunocin for immunomodulatory activity. Indian J Pharma Sci 2000;62(4):257-60.

21. Misra HP, Fridovich I. The role of superoxide anion in the autooxidation of epinephrine and a simple assay for SOD. J Biol Chem 1972;247:3170-5.

22. Maechlay AC, Chance B. The assay of catalase and peroxidase. Methods of Biochemical Analysis. Interscience Inc., New York 1954:357-424.

23. Yagi K. Lipid peroxides and human disease. Chem Physiol Lip 1978;45:337-57.

24. Ellmann GL. Tissue Sulfhydryl groups. Arch Biochem Biophys 1959;82:70-7.

25. Suneetha S. Histopathological techniques. Handbook of CMAI Medical Laboratory Technology by Robert H Gaman 1993;508-41.

26. Shinde UA, Phadke AS, Nair AM, Mungantiwar AA, Dikshit VJ, Saraf MN. Preliminary studies on the immunomodulatory activity of Cedrus deodara wood oil. Fitoterapia. 1999;70(4):333-9.

27. Srikumar R, Parthasarathy NJ, Devi RS. Immunomodulatory activity of triphala on neutrophil functions. Biol Pharm Bull 2005;28(8):1398-403.

28. Gokhale AB, Damre AS, Saraf MN. Investigations into the immunomodulatory activity of Argyreia speciosa. J Ethnopharmacol 2003;84:109-14.

29. Dash S, Nath LK, Bhise S, Kar P, Bhattacharya S. Stimulation of immune function activity by the alcoholic root extract of Heracleum nepalense D. Don. Ind J Pharmacol 2006;38(5):33640.

30. Smit HF, Kroes BH, Van den Berg AJ, Van der Wal D, Van den Worm E, Beukelman CJ, et al. Immunomodulatory and anti-inflammatory activity of Picrorhiza scrophulariiflora. J Ethnopharmacol 2000;73(1):101-9.

31. Pan MH, Chiou YS, Tsai ML, Ho CT. Anti-inflammatory activity of traditional Chinese medicinal herbs. J Tradit Complement Med 2011;1(1):8-24.

32. Zhai Z, Solco A, Wu L, Wurtele ES, Kohut ML, Murphy PA, et al. Echinacea increases arginase activity and has anti-inflammatory properties in RAW 264.7 macrophage cells, indicative of alternative macrophage activation. J Ethnopharmacol 2009;122(1):76-85.

33. Classen A, Lloberas J, Celada A. Macrophage activation: classical vs. alternative. In: Macrophages and Dendritic Cells 2009:29-43.

34. Brombacher F, Arendse B, Peterson R, Holscher A, Holscher C. Analyzing classical and alternative macrophage activation in macrophage/neutrophil-specific IL-4R $\alpha$-deficient mice. Methods Mol Biol 2009; 531:225-52.

35. Janero DR. Malondialdehyde and thiobarbituric acid-reactivity as diagnostic indices of lipid peroxidation and peroxidative tissue injury. Free Radical Biol Med 1990;9:515-40. 
www.ijpsonline.com

36. Mehta RL, Kellum JA, Shah SV, Molitoris BA, Ronco C, Warnock DG, et al. Acute Kidney Injury Network: report of an initiative to improve outcomes in acute kidney injury. Crit Care 2007;11:1-8. 